\title{
Oligocene niche shift, Miocene diversification - cold tolerance and accelerated speciation rates in the St. John's Worts (Hypericum, Hypericaceae)
}

\author{
Nicolai M Nürk ${ }^{1 *}$, Simon Uribe-Convers ${ }^{2}$, Berit Gehrke ${ }^{3}$, David C Tank ${ }^{2}$ and Frank R Blattner ${ }^{4,5}$
}

\begin{abstract}
Background: Our aim is to understand the evolution of species-rich plant groups that shifted from tropical into cold/ temperate biomes. It is well known that climate affects evolutionary processes, such as how fast species diversify, species range shifts, and species distributions. Many plant lineages may have gone extinct in the Northern Hemisphere due to Late Eocene climate cooling, while some tropical lineages may have adapted to temperate conditions and radiated; the hyper-diverse and geographically widespread genus Hypericum is one of these.
\end{abstract}

Results: To investigate the effect of macroecological niche shifts on evolutionary success we combine historical biogeography with analyses of diversification dynamics and climatic niche shifts in a phylogenetic framework. Hypericum evolved cold tolerance c. 30 million years ago, and successfully colonized all ice-free continents, where today $\sim 500$ species exist. The other members of Hypericaceae stayed in their tropical habitats and evolved into 120 species. We identified a 15-20 million year lag between the initial change in temperature preference in Hypericum and subsequent diversification rate shifts in the Miocene.

Conclusions: Contrary to the dramatic niche shift early in the evolution of Hypericum most extant species occur in temperate climates including high elevations in the tropics. These cold/temperate niches are a distinctive characteristic of Hypericum. We conclude that the initial release from an evolutionary constraint (from tropical to temperate climates) is an important novelty in Hypericum. However, the initial shift in the adaptive landscape into colder climates appears to be a precondition, and may not be directly related to increased diversification rates. Instead, subsequent events of mountain formation and further climate cooling may better explain distribution patterns and species-richness in Hypericum. These findings exemplify important macroevolutionary patterns of plant diversification during large-scale global climate change.

Keywords: Adaptive landscape, BAMM, Bayou, Divergence time estimation, Climate change, Cold tolerance, Diversification rate shifts, Historical biogeography, Hypericum (St. John's wort, Hypericaceae), Niche shift

\section{Background}

At the onset of evolutionary theory it was observed that "species of the same genus have usually [...] some similarity in habits and constitution" ([1], p 76). That is, closely related species or lineages are expected to be more similar in ecology than to more distantly related taxa because of their more recent common ancestry $[2,3]$. Accordingly, it has been observed that under changing environmental conditions organisms tend to retain

\footnotetext{
*Correspondence: n.nuerk@cos.uni-heidelberg.de

'Centre for Organismal Studies Heidelberg, University of Heidelberg,

Im Neuenheimer Feld 345, 69120 Heidelberg, Germany

Full list of author information is available at the end of the article
}

their ancestral ecological characteristics rather than evolving into a new ecological niche [4-6].

Large-scale global climate change dramatically alters the distribution of major biomes [7], and thus the ecological niches available to entire taxonomic groups [8,9]. During the Early Eocene Climatic Optimum, c. 55 million years $(\mathrm{Ma})$ ago, tropical biomes dominated the Earth's surface even at high latitudes [10]. Within the last $50 \mathrm{Ma}$, however, the world has experienced a transition: a fluctuating but overall decrease in mean temperatures $[7,11,12]$ that shifted the distribution of frost-intolerant plants towards the equatorial zones. The flowering plant families Araceae [13], Chloranthaceae [14], 
and Malpighiaceae [15] are well-studied examples of formerly more widely distributed lineages that are currently mostly restricted to the tropics.

Only some lineages of flowering plants have managed the transition from tropical to temperate climates $[16,17]$, despite presumably having had ample opportunities to do so with the Neogene expansion of temperate habitats $[18,19]$. Adaptation to cold is supposed to involve complex reorganizations of the genome and physiology [20], implying that the evolution of tolerances to temperate climates with highly seasonal conditions may pose particular problems $[21,22]$, especially for warmadapted plant taxa confronted with cooling climate [19]. In contrast, all extant plant lineages that do occur in temperate areas underwent adaptation to cooler climates at some point $[23,24]$. Also, in an area that undergoes environmental changes and that lacks suitable migration routes, only such resident lineages will survive that can develop the relevant traits necessary to persist [25-27]. In a recent study of angiosperms, Zanne et al. suggest that "many of these solutions were probably acquired before their foray into the cold" [24]. On the other hand, it has been suggested that in the absence of obvious key innovations, climate cooling may have acted as an important driver of diversification, e.g., in the hyper-diverse genus Carex [28].

We provide a macroevolutionary study of the genus Hypericum L. (St. John's Worts, Hypericaceae Juss.) in the context of changing global climate conditions during the Neogene. Hypericum belongs to the clusioid clade of the Malpighiales [29,30], which, apart from Hypericum, is almost exclusively composed of tropical taxa (Figure 1). More than $80 \%$ of the known species within the family Hypericaceae occur within Hypericum [31,32]; the remaining 20\% consist of tropical plants from four genera [33] in the tribes Vismieae Choisy (Vismia Vand., and Harungana Lam., incl. Psorospermum Spach) and
Cratoxyleae Benth. \& Hook.f. (Cratoxylum Blume and Eliea Cambess. [34]).

Hypericum has a nearly cosmopolitan distribution (Figure 1) with a primary center of species-richness in the temperate regions of Eurasia [35,36]. In temperate regions, Hypericum species are mostly native to lowand mid-elevation areas, while in the tropics they are almost always confined to high-elevation mountains, such as the South American Andes or mountains in topical Africa [37]. The divergence time of the Hypericum crown node has been estimated to the Upper Eocene, $c$. $35 \mathrm{Ma}$ ago [38], based on a single (seed-) fossil calibration. The same study reconstructed the Western Palearctic as the ancestral area for Hypericum. However, Sánchez Meseguer et al. [38] employed a Bayesian approach $[39,40]$ that limits ancestral areas to only single states in the reconstruction (i.e. it is not possible to infer the occurrence of ancestral populations in multiple areas). For a genus like Hypericum that has several species that span very wide geographic ranges, this assumption is likely inadequate.

Within an otherwise pantropic clade [30] Hypericum is a cold-adapted but species-rich lineage. Because the clade is of worldwide cold/temperate distribution and evolved during the Paleaogene to Neogene (23.3 Ma [41]) climate transition, Hypericum is ideal for studying the effects of broad-scale climate change on plant distribution and diversification. Furthermore, the evolution of morphological characters in the genus has been studied at length [36-38,42], providing a foundation to further investigate evolutionary patters and processes in Hypericum.

In this study, we test the hypotheses that (i) Hypericum originated in the Western Palearctic prior to the Oligocene, as suggested by Meseguer et al. [38], that (ii) the occupation of temperate environments is derived in the Hypericaceae and a distinctive characteristic of Hypericum, and that

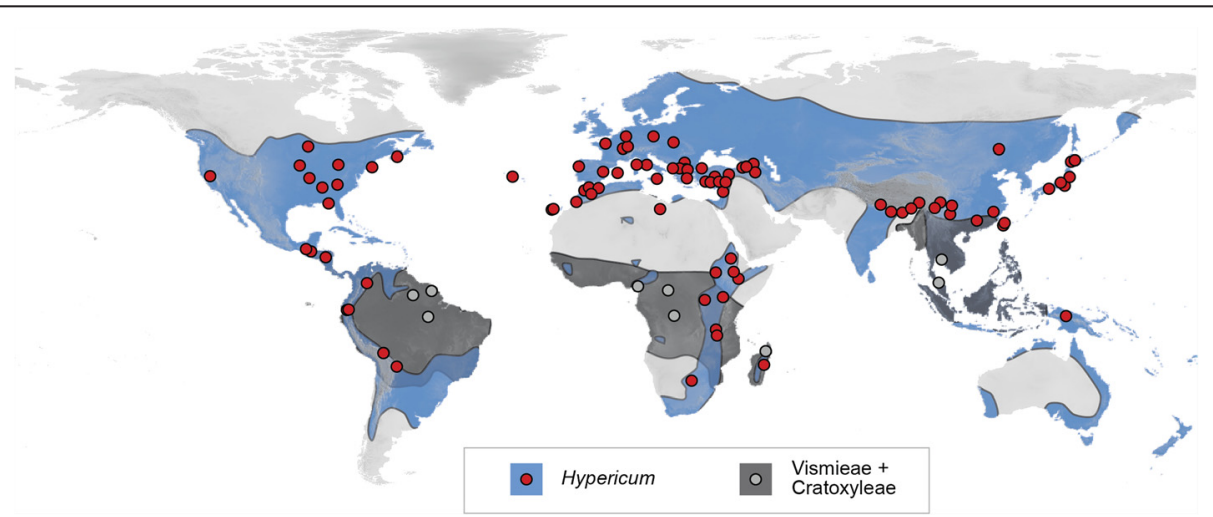

Figure 1 Distribution map of Hypericaceae and collection sites. Blue shading and collection sites (points) in red mark the distribution of Hypericum (Hypericeae). Grey shading and collection sites in light-grey mark the distribution of the tropical members of the family (Cratoxyleae and Vismieae). 
(iii) it has stimulated the radiation of this lineage globally. To do so, we estimate a species phylogeny based on nuclear and chloroplast sequence variation. We calibrate our time-tree using six fossils and compare the effect on node ages of the specific assignment of the oldest known fossil in Hypericum. To evaluate historical biogeography, we employ parametric models that allow for the incorporation of paleogeographic information. Applying recently developed Bayesian approaches, we estimate the magnitude and placement of climatic niche shifts, and investigate the impact of the transition from the tropical into the cold/temperate climate niche by assessing the placement of shifts in diversification rates.

\section{Results}

\section{Hypericaceae phylogenetics}

Maximum likelihood (ML) topologies were similar for both chloroplast (pet $\mathrm{D}+\operatorname{trn} \mathrm{L}-\operatorname{trn} \mathrm{F}$ ) and nuclear (ITS) data. Discordance between nuclear and chloroplast trees was present only in two places, although without strong support (Additional file 1: Phylogenetic inference). Thus, we concatenated the chloroplast and nuclear sequence data into a combined data set, which contained $24.1 \%$ missing data $(0.1 \%$ missing in ITS, $21.2 \%$ in petD, and $59.4 \%$ in $\operatorname{trn} \mathrm{L}-\operatorname{trn} \mathrm{F})$.

We included 100 representative species (103 accessions; online Additional file 1: Voucher) in the combined sequence data set that contained 2024 nucleotide positions after alignment and removal of ambiguous sites. Phylogenetic inference revealed the same major groups as reported in other studies $[37,38,43,44]$, but with strong support (Additional file 1: Figure S1). Most basal splits within Hypericum, however, lack sufficient support, a result also revealed in previous studies that included deeper sampling [37,38]. Ten major clades consistent with current taxonomy are present within Hypericaceae (Figure 2 and Additional file 1: Figure S1), allowing us to assign species richness to each clade for comparative analyses (Figure 3).

\section{Divergence times depend on fossil assignment}

Bayesian estimation of divergence times was done by assigning the oldest known fossil in Hypericum as a minimum time constraint to (A) the stem node, and (B) to the crown node of Hypericum (Additional file 1: Calibration; Additional file 1: Figure S2). For both analyses, we tested the effect of missing data on age estimates using a reduced data set that did not contain any missing data. Results of the complete sampling and the reduced data sets were congruent, regardless of the calibration approach used, deviating maximally at the Hypericum node with less than $1.6 \mathrm{Ma}$ in mean ages (Table 1).
Divergence time estimates produced by the two analyses (A and B) differed by $\sim 10$ million years at the $H y$ pericum crown node (Table 1 and Additional file 1: Table S1). Analysis A is congruent with $\mathrm{Xi}$ et al. [30], which focused on family level relationships and estimated divergence times within Malpighiales using 82 chloroplast DNA regions and 16 external fossil calibrations. In analysis B the inferred crown age is $c .8$ million years older for the Hypericaceae (the most recent common ancestor [MRCA] of Hypericum, Vismieae, and Cratoxyleae; Table 1 and Additional file 1: Table S1) compared to $\mathrm{Xi}$ et al. [30]. It is conservative to assign a fossil to a stem node given that a hard minimum time constraint is used for calibration [45]. Therefore, we use the divergence time estimate of analysis A (fossil assignment to the stem node; mean crown age of Hypericum 25.9 Ma [33.3-19.6 95\% HPD]; Table 2, Additional file 1: Figure S2) to discuss the results of the biogeographic optimization, diversification analyses, and climatic niche shifts in the historic context (results of these analyses using both divergence time estimations are given in the supplementary materials; Additional file 1: Table S1, S2, and S3, Figures S4 and S5).

\section{Ancestral area estimation is equivocal at the Hypericum crown node}

Ancestral areas were optimized over both divergence time estimations taking phylogenetic uncertainty into account by analyzing a posterior subset of 1000 trees. Additionally, two models were compared which differed in their dispersal/extinction probabilities both between areas and over time; a stratified M1 model that accounts for varying connectivity of areas over time (Additional file 1: Figure S3), and a unconstrained M2 model with equal probabilities of movement between areas at any time (i.e. equal dispersal/extinction probabilities). The ancestral areas estimated per node were highly congruent in all analyses, except for four nodes for which the ancestral states differed (Additional file 1: Table S2). Two of these affected nodes are located at basal dichotomies, one at the Hypericum crown node (Figure 2), and one at the 'Ascyreia s.l.' crown node. In all four cases of incongruence, and independent of the used age estimation, the evidence ratio [46] is generally higher in the stratified model when compared to unconstrained model (Additional file 1: Table S2).

\section{Niche shifts during the evolution of the Hypericum stem lineage in the Oligocene}

We used the first principal components (PC1) scores obtained from a phylogenetic PCA as an approximation of the climatic niche. The PC1 scores were dominated by the thermal bioclim variables (bio1-11; with the most influence from mean annual temperature [bio1]), and 


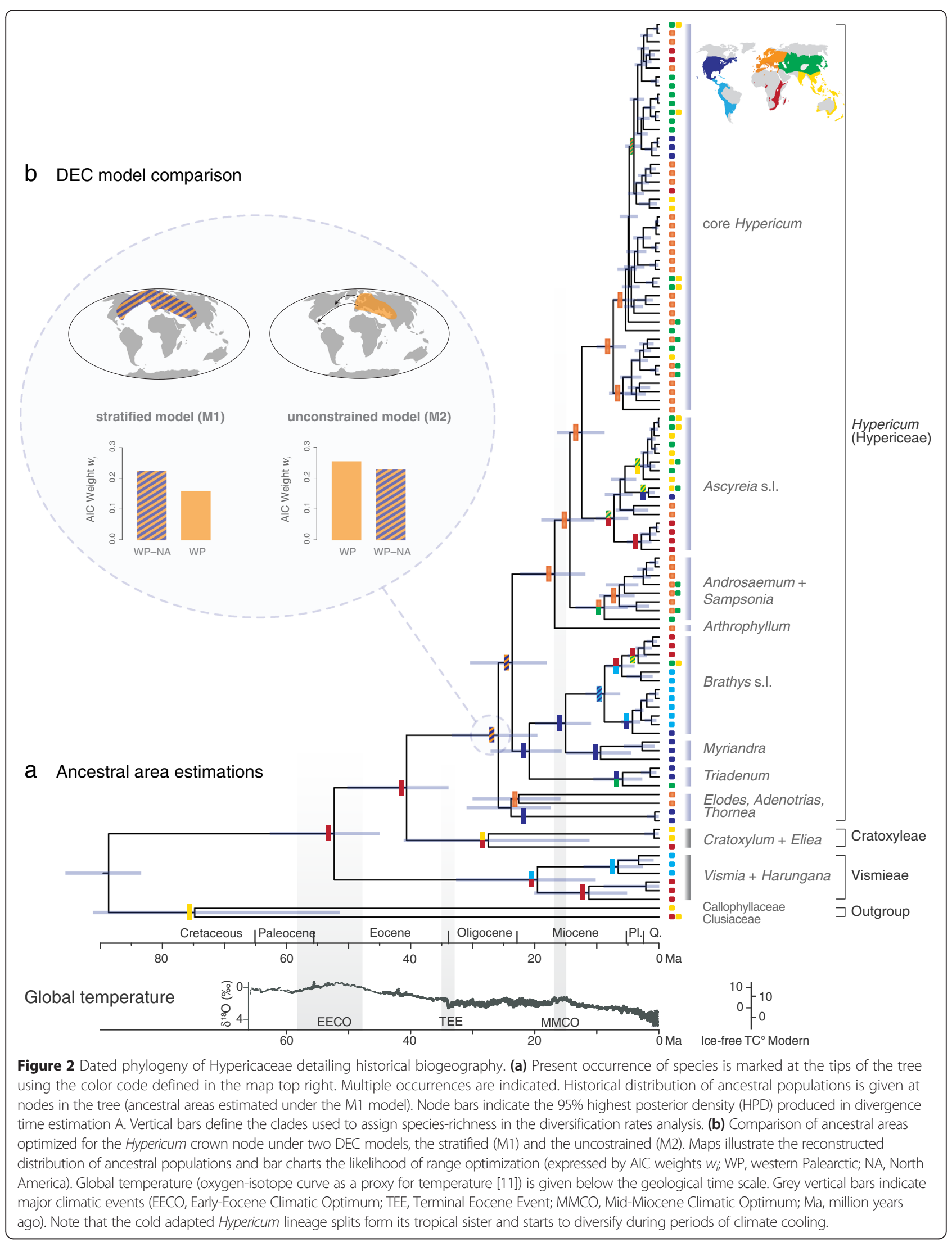




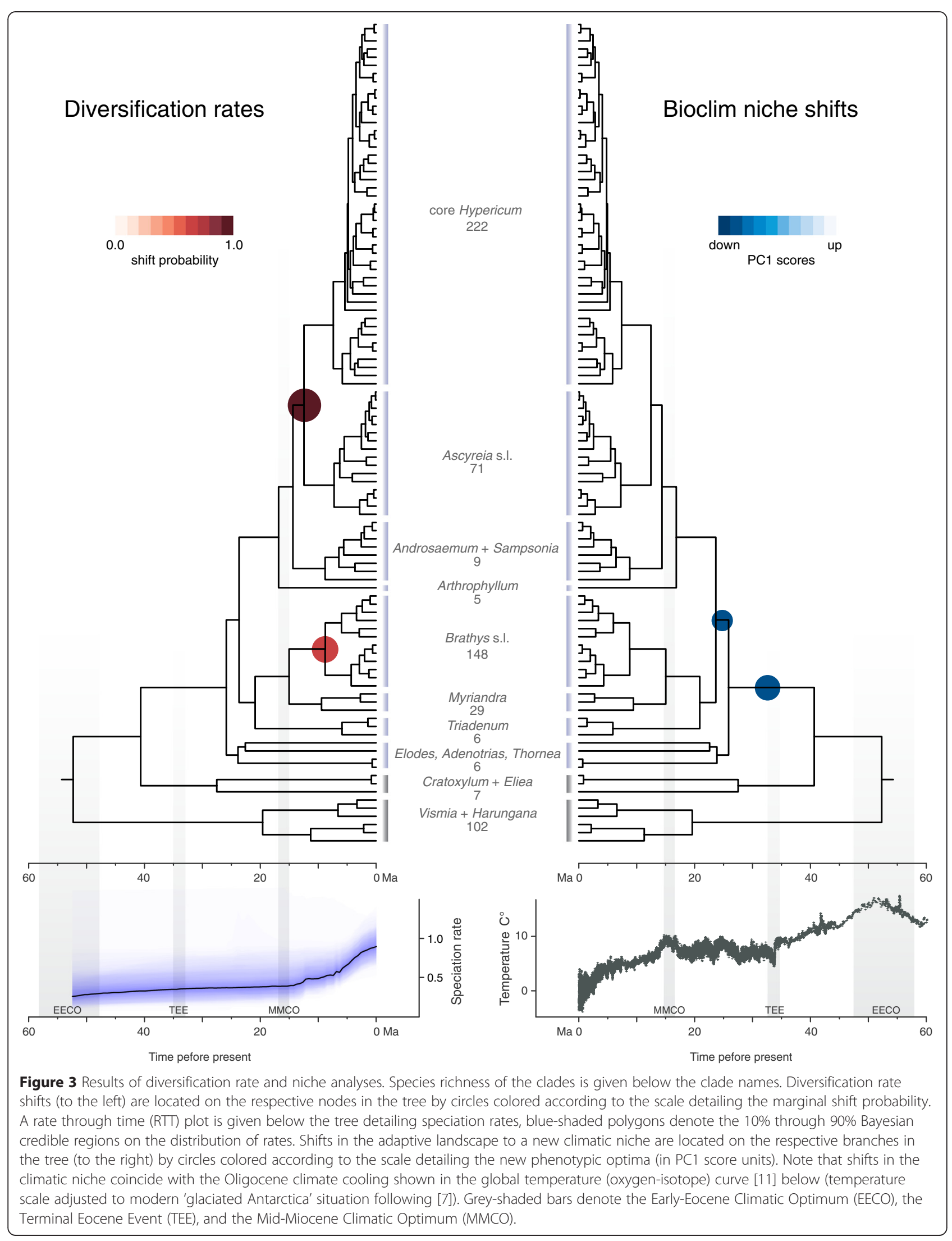


Table 1 Results of divergence time estimation using different fossil assignments

\begin{tabular}{|c|c|c|c|c|}
\hline \multirow[t]{3}{*}{ Node (mrca) } & \multicolumn{4}{|c|}{ Bayesian relaxed clock - crown ages } \\
\hline & \multicolumn{2}{|l|}{ Analysis A } & \multicolumn{2}{|l|}{ Analysis B } \\
\hline & complete sampling & 'no missing' data & complete sampling & 'no missing' data \\
\hline \multirow[t]{2}{*}{ Hypericaceae } & 52.31 & 53.13 & 59.63 & 57.22 \\
\hline & $(62.66-45.00)$ & $(64.05-45.15)$ & $(71.25-49.26)$ & $(69.06-47.94)$ \\
\hline \multirow[t]{2}{*}{ Vismieae } & 19.59 & - & 23.25 & - \\
\hline & $(32.66-10.22)$ & & (37.69-12.73) & \\
\hline \multirow[t]{2}{*}{ Cratoxyleae } & 27.52 & - & 32.50 & - \\
\hline & $(41.08-11.23)$ & & $(48.89-14.38)$ & \\
\hline \multirow[t]{2}{*}{ Hypericum } & 25.87 & 27.45 & 35.20 & 35.77 \\
\hline & (33.32-19.59) & $(36.50-19.00)$ & $(39.31-33.90)$ & $(40.97-33.90)$ \\
\hline \multirow[t]{2}{*}{ Brathys s.l. + Myriandra } & 15.03 & 16.12 & 19.63 & 20.70 \\
\hline & $(19.99-10.99)$ & $(22.67-10.77)$ & $(24.56-14.87)$ & $(26.52-15.01)$ \\
\hline \multirow[t]{2}{*}{ Brathys s.l. } & 8.77 & 8.97 & 11.08 & 11.24 \\
\hline & $(11.82-6.26)$ & $(13.06-5.76)$ & $(14.63-7.94)$ & $(15.28-7.71)$ \\
\hline \multirow[t]{2}{*}{ core Hypericum + Ascyreia s.l. } & 12.46 & 12.65 & 15.86 & 15.54 \\
\hline & $(16.44-8.80)$ & $(18.00-8.40)$ & $(20.63-11.66)$ & $(21.17-10.80)$ \\
\hline
\end{tabular}

Mean crown ages in Ma are given with the 95\% HPD in brackets below. HPD, highest posterior density; Ma, million years.

Both calibration approaches (A and B) are detailed, and results of analyses A and B repeated using the reduced data set that did not contain missing sequence data ('no missing' data).

account for c. $34 \%$ of the variation within the data. Bayesian fitting of multi-optima OU models to the approximation of the climatic niche space estimated the placement and magnitude of two shifts. Both shifts were estimated to have occurred in the Oligocene, the first shift during the evolution of the stem lineage of Hypericum, and the second shift one divergence event latter at the stem lineage of the MRCA of 'core Hypericum' - 'Triadenum (Table 2; for a comparison of results produced under the two age estimations see Additional file 1: Figure S5, Table S3). Both shift magnitudes were negative, indicating a niche shift into colder climates during the early

Table 2 Summary statistics detailing node support, age estimation, diversification rates, and niche shifts

\begin{tabular}{|c|c|c|c|c|c|c|}
\hline \multirow[t]{2}{*}{ Node (mrca) } & \multirow{2}{*}{$\begin{array}{l}\text { Node support } \\
\text { (pp|ML) }\end{array}$} & \multirow{2}{*}{$\begin{array}{l}\text { Crown age* } \\
(\mathrm{Ma})\end{array}$} & \multicolumn{2}{|c|}{ Diversification rates* } & \multicolumn{2}{|c|}{ Bioclimatic niche shifts* } \\
\hline & & & shift probability & speciation rate & $\mathrm{pp}$ & phenotypic optimum \\
\hline \multirow[t]{2}{*}{ Hypericaceae } & $1 \mid 100$ & 52.31 & - & 0.66 & - & 0.00 \\
\hline & & $(62.66-45.00)$ & & $(0.46-0.88)$ & & \\
\hline \multirow[t]{2}{*}{ Vismieae } & $1 \mid 100$ & 19.59 & - & 0.43 & - & 1.63 \\
\hline & & $(32.66-10.22)$ & & $(0.19-0.83)$ & & $(0.07)$ \\
\hline \multirow[t]{2}{*}{ Cratoxyleae } & $.56 \mid 60$ & 27.52 & - & 0.41 & - & 1.11 \\
\hline & & $(41.08-11.23)$ & & $(0.18-0.81)$ & & $(0.15)$ \\
\hline \multirow[t]{2}{*}{ Hypericum } & $1 \mid 100$ & 25.87 & - & 0.75 & 0.53 & -4.24 \\
\hline & & $(33.32-19.59)$ & & $(0.54-1.0)$ & & $(0.01)$ \\
\hline \multirow[t]{2}{*}{ core Hypericum - Brathys s.l. } & $.83 \mid 65$ & 23.67 & - & 0.83 & 0.34 & -4.40 \\
\hline & & $(30.41-18.08)$ & & $(0.59-1.08)$ & & $(0.01)$ \\
\hline \multirow[t]{2}{*}{ Brathys s.l. } & $1 \mid 100$ & 8.77 & 0.64 & 1.04 & - & -3.67 \\
\hline & & $(11.82-6.26)$ & & $(0.54-1.75)$ & & $(0.06)$ \\
\hline \multirow[t]{2}{*}{ core Hypericum + Ascyreia s.l. } & $1 \mid 99$ & 12.46 & 0.93 & 1.06 & - & -4.67 \\
\hline & & $(16.44-8.80)$ & & $(0.75-1.51)$ & & $(0.03)$ \\
\hline
\end{tabular}

*Results produced using age estimation A. For the diversification rate analysis, detected shifts are marked by their probability. The mean speciation rate (species/ $\mathrm{Ma}$ ) per clade is detailed with the $5 \%$, and $95 \%$ HPD in brackets below. For the bioclimatic niche analysis, shifts are marked by their probability, and the new phenotypic optimum (PC1 score optimum) is detailed with the standard error in brackets below. HPD, highest posterior density; pp, posterior probability; ML, maximum likelihood bootstrap support; Ma, million years; shift probability, marginal probability of rate shifts. 
evolution of Hypericum (Table 2 and Additional file 1: Table S3). The phylogenetic half-life $(\ln (2) / \alpha=0.009$ $\mathrm{Ma}$; based on a rate of adaptation of $\alpha=1.525$, and a total tree length of $52.31 \mathrm{Ma}$ ) signifies that the movement to the primary climatic optimum in Hypericum was rapid and resembles an OU process rather than Brownian motion [47].

\section{Diversification rate shifts in Hypericum in the Miocene}

In the Hypericaceae, two shifts in diversification dynamics were detected within Hypericum with strong support: (i) at the stem lineage of 'core Hypericum + Ascyreia s.l.', and (ii) with the divergence of Central- and South American 'Brathys s.l.' from its relatives (Figure 3, Table 2). In both dating approaches, the same clades are identified to show diversification rate shifts comparing the Bayesian credible sets of distinct shift configurations (Additional file 1: Figure S4). In the analysis using the dating approach $\mathrm{A}$, the first increase in diversification rates is inferred to have occurred at about 13.93 Ma with a marginal probability of 0.93 , and the second at about 12.54 Ma with a marginal probability of 0.64 , resulting in a rate of 1.04 and 1.06 species per million year, respectively (for a comparison of results see Additional file 1: Figure S4, Table S3).

\section{Discussion}

\section{Historical biogeography of Hypericaceae}

There is strong evidence that the MRCA of Hypericaceae occurred in Africa in the Eocene (Figure 2), a result also recovered in a previous study [38]. The MRCAs of the tropical taxa within the Hypericaceae (Cratoxyleae and Vismieae) are revealed to have occurred in Africa + Southeastern Asia and Africa + South America, respectively. During the Early Eocene the higher thermal maximum allowed megathermal organisms, such as the MRCA of Hypericaceae, to disperse throughout the Northern Hemisphere, which explains the vicariance of many tropical lineages $[10,19,48]$.

At the onset of worldwide climate cooling, c. $40 \mathrm{Ma}$ the Hypericum stem lineage split from its tropical relatives. The ancestral area estimated for the MRCA of $\mathrm{Hy}$ pericum is in the Northern Hemisphere, either solely in the Western Palaearctic, or more widely distributed between the Western Palaearctic and the Nearctic (Figure 2, Additional file 1: Table S2). The Nearctic has been connected to the Western Palearctic through islands that could have easily functioned as stepping-stones facilitating dispersal over the North Atlantic [49-51]. Seeds of $\mathrm{Hy}$ pericum are tiny, ca. 1.5 to $2.5 \mathrm{~mm}$ long, and are easily dispersed by birds or strong winds [32], promoting long-distance dispersal. However, an ancestral distribution from the Western Palaearctic to the Nearctic is somewhat surprising given the fact that the oldest known fossil is from Siberia and SW China [52]. Differential extinction may explain the partial absence of reconstructed ancestral populations in the areas of the oldest fossil record [38]. Hence, the assumption of a widespread MRCA of Hypericum from the Palaearctic to the Nearctic connected via Beringia $[19,53]$ would be plausible as well. On the other hand, it is likely that the fossil record does not accurately represent actual ancestral distributions, and thus, may be misleading for ancestral area estimations. Regardless, Hypericum is of Northern Hemisphere origin, likely around the late Tethys estuaries in the Palaearctic [37], perhaps as part of a deciduous mixed-mesophytic forest [54]. The ecology of basal lineages within Hypericum, however, is diverse reaching from dry rocky Mediterranean to shallow aquatic habitats, and montane cloud forests. Thus, extensive differential extinction of intermediate ancestral populations (ecologically and geographically) and/or intercontinental long-distance colonization early in the evolutionary history is needed to explain biogeographic patterns in Hypericum.

\section{Cold adaptation in the Hypericum stem lineage but later diversification}

Initially, no speciation seems to have taken place in $H y$ pericum - or extinction may have erased the evidence of earlier divergence in the genus leading to a stem lineage of c. 15 million years (c. 40-25 Ma). However, the genesis of modern species diversity in Hypericum traces to c. $25 \mathrm{Ma}$ (Figures 2 and Additional file 1: Figure S2), after the Oligocene climate cooling caused a substantial decrease in mean temperatures [11]. This worldwide cooling, which led to a period of rather constant cold temperatures [55], initiated the expansion of temperate habitats in the Northern Hemisphere, replacing the more tropical vegetation dominant during the Eocene [10]. With the exception of Hypericum, the remaining lineages of Hypericaceae stayed in tropical climates, i.e. their distributions experienced a restriction with the retreat of tropical areas towards equatorial zones after the Eocene Thermal Maximum [10]. In contrast, Hypericum adapted to colder climates c. $30 \mathrm{Ma}$ (Figure 3) and consequently dispersed and diversified in temperate habitats. The adaptation towards the new climatic optimum (estimated by the phylogenetic half-life [56]) was rapid, meaning that Hypericum species were well adapted to the cold/temperate niche [47]. Hence, following this initial niche shift, Hypericum never completely left the colder climates. Even in equatorial areas, Hypericum is only found at high elevations with a cool climate, such as the South American Andes and the high mountains of Africa.

Two shifts in diversification rates were detected with strong support in Hypericum (Figure 3). The first is an 
increase in speciation rates that coincides with a sudden decrease of temperature during the Middle Miocene Climate Transition at about $14 \mathrm{Ma}$ [11]. The second increase in speciation rates was likely the result of dispersal into the South American continent and may have been triggered by the orogeny of the Andes [43]. That is, the adaptation of Hypericum to colder climates first evolved during the Oligocene but diversification rates increased c. 13-17 million years later during the Miocene, in nested clades within Hypericum. The evolution of a shrubby habit at the Hypericum stem lineage [37] might well be a life history trait that facilitated the initial adaptation to cold [24], but no obvious intrinsic (morphological or physiological) traits that could be interpreted as key innovations were identified for these rapidly diversifying clades $[37,38]$. However, our results suggest that cold tolerance is likely an important initial adaptation that was exploited when new biogeographic opportunities were presented (i.e. Andean orogeny). Only after a long lag phase when global temperatures dramatically decreased following the Mid-Miocene Thermal Optimum [11], did changing environments and expanding temperate regions (including tropical high mountains) allow Hypericum to spread and diversify. Because c. $42 \%$ of extant Hypericum species are found in montane biomes (c. $72 \%$ of this diversity in tropical high mountains), we postulate that the onset of extensive mountain formation in Eurasia and the Americas [57] is likely to have contributed to both detected rate shifts.

\section{Conclusion}

After divergence from its tropical relatives, adaptation towards colder climates $c$. $30 \mathrm{Ma}$ ago enabled Hypericum to stay in the Northern Hemisphere, while its tropical relatives experienced habitat restriction towards equatorial zones. This niche shift offered dispersal and possible diversification opportunities in the expanding temperate areas in the Northern Hemisphere during the Oligocene. After the last thermal maximum in the Miocene, massive mountain formations and further climate cooling may have stimulated the radiation of this lineage globally. As a consequence, cold-adapted Hypericum contains $80 \%$ of the species present in the family. Despite its worldwide distribution and tropical ancestry, even the species growing in the tropics retain their temperate climate niche by growing exclusively in cool climates of higher elevation habitats.

Higher species richness in temperate climates is rather atypical and contrary to the usual pattern observed in plants where tropical groups generally tend to have more species than temperate relatives $[6,23]$. However, our findings mirror patterns described in sedges (Carex) [28], and to varying extents in buttercups (Ranunculaceae) [58], grasses (Poaceae) [59-62], and heaths (Ericales) [63].
We have demonstrated that a pronounced lag phase is present between the initial niche shift and diversification in new habitats. Therefore, we conclude that the disproportionate species numbers of Hypericum in comparison to its tropical relatives are not only a result of initial cold-climate adaptation. Our analyses indicate a relatively late increase in speciation rate, i.e. with the onset of further cooling and especially mountain formation during the Upper Miocene (and Pliocene). Likewise, Carex, the most diverse non-tropical sedge lineage (Cyperaceae) [28] has a stem lineage of c. 20 million years, with most extant lineages having diversified subsequent to the Oligocene in montane biomes. Thus, we emphasize that both $(i)$ a niche shift following the Eocene Thermal Optimum as a precondition for the presence of cold-adapted lineages in temperate regions, and (ii) an extrinsic trait (perhaps in addition to lineagespecific intrinsic traits), i.e. the availability of emerging temperate and/or mountain habitats, are key events potentially triggering diversification rates in these coldadapted, species-rich plant groups.

\section{Methods}

Taxon sampling and species richness

Plant material from herbarium specimens or silica dried samples were chosen for 100 species (and 3 subspecies) representing the distribution range of all major lineages present in Hypericaceae [30,37] (see Additional file 1: Voucher). Following Xi et al. [30], Garcinia xanthochymus Hook.f. ex T.Anderson (Clusiaceae Lindl.) was chosen as outgroup in the phylogenetic analyses.

The monograph of Hypericum [31,32,42,64-72] was used for data on species richness and distribution (for Hypericum sensu Robson 2012). Stevens [34] lists information for the remaining taxa of Hypericeae Choisy (Triadenum Raf., Thornea Breedlove \& E.M.McClint., and Lianthus N.Robson; included in Hypericum in Ruhfel et al. [33]), as well as the tropical genera of the family Hypericaceae. Xi et al. [30] provides information on distributions for Clusiaceae and Calophyllaceae J.Agardh (Additional file 1: Voucher). Total species numbers with evidence from taxonomy [32], morphological cladistics [36], and molecular phylogenetic analyses $[37,38]$ were used to assign species richnesses to the major clades defined in the diversification rate analyses.

\section{Molecular marker and sequencing}

We sequenced two fragments from the chloroplast genome, namely pet $\mathrm{D}$ (including the pet $\mathrm{B}-$ pet $\mathrm{D}$ intergenic spacer, the pet $\mathrm{D}-5^{\prime}$-exon, and the pet $\mathrm{D}$ intron) and $\operatorname{trn} \mathrm{L}-\operatorname{trn} \mathrm{F}$ (including the $\operatorname{trn} \mathrm{L}^{\mathrm{UAA}}$ intron and the intergenic spacer between the $\operatorname{trn} \mathrm{L}^{\mathrm{UAA}} 3^{\prime}$ exon and $\operatorname{tr} n \mathrm{~F}^{\mathrm{GAA}}$ gene), and the nuclear rDNA internal transcribed spacer 
region (including ITS-1, 5.8S rDNA, and ITS-2). Extraction of DNA was done according to Nürk et al. [37]. In the case of well preserved herbarium material or silica dried samples, entire regions were amplified using the primers ITS-A(F) and ITS-B(R) [73], PIpetB1411F and PIpetD738R [74], $c(F)$ and $f(R)$ designed by Taberlet [75] for the $\operatorname{trn} \mathrm{L}-\operatorname{trn} \mathrm{F}$ region. In the case of degraded herbarium materials, ITS-1 and ITS-2 were amplified separately using in addition two internal primers, ITS-C(R) and ITS-D(F) binding in the conserved 5.8S rDNA [73]. Similarly for pet $\mathrm{D}$, using the two internal primers SALpetD599F and OpetD897R designed by Korotkova et al. [76]. PCR amplification of ITS was performed as described in Nürk et al. [37]. PCR reaction mixes for pet $\mathrm{D}$ and $\operatorname{trn} \mathrm{L}-\operatorname{trn} \mathrm{F}$ were chosen according to Nürk et al. [37], but without adding $\mathrm{MgCl}_{2}$, and PCR profiles consisted of an initial denaturation at $96^{\circ} \mathrm{C}$ for 1.5 min, followed by 35 cycles of $95^{\circ} \mathrm{C}$ for $30 \mathrm{~s}, 50^{\circ} \mathrm{C}$ for $60 \mathrm{~s}, 73^{\circ} \mathrm{C}$ for $90 \mathrm{~s}$ and a final step at $72^{\circ} \mathrm{C}$ for $10 \mathrm{~min}$. Primer combinations as described above for poorly preserved samples were used for cycle sequencing. DNA sequencing was done by Eurofins MWG Operon (Ebersberg, Germany). All newly generated sequences have been submitted to the to the EMBL nucleotide database (Accession No. LK871650-LK871782).

\section{Phylogenetic inference}

Sequences were assembled and edited with Geneious v5.4 [77], aligned using the automatic selection of an appropriate strategy in Mafft v6.903b [78,79] and manually adjusted using PhyDE v0.996 (available online: http:// www.phyde.de). In order to remove poorly aligned or length variable data partitions the alignments were subjected to Gblocks 0.91b sever [80] with the "less stringent' options selected.

Phylogenetic analyses were performed under maximum likelihood (ML) [81] and Bayesian inference (BI) [82] to reveal confidence limits of the data. ML analyses were performed with the RAxML GUI v1.1 [83,84] and $\mathrm{BI}$ in MrBayes 3.2.2 [85]. To test for discordance we analyzed the nuclear (ITS) and chloroplast data partitions (pet $\mathrm{D}, \operatorname{trn} \mathrm{L}-t r n \mathrm{~F})$ separately by $\mathrm{ML}$ search under the GTRCAT model of sequence evolution. Clade support was evaluated with 1000 rapid bootstrap replicates [86].

The combined data set (ITS + pet $\mathrm{D}+\operatorname{trn} \mathrm{L}-\operatorname{trn} \mathrm{F})$ was analyzed under ML with the partitions defined and the settings chosen as described for the ML analysis above. For BI we started 4 simultaneous runs, each with 4 chains, set to run $10^{8}$ cycles, with sampling every $10^{4}$ cycle, setting temperature to 0.01 , and with the appropriate model of sequence evolution specified per partition: GTR $+\mathrm{I}+\Gamma$ for ITS and petD and $\mathrm{HKY}+\mathrm{I}+\Gamma$ for trnL-trnF; selected in MrModeltest [87] under the Akaike Information Criterion (AIC) [88]. We used the
ML tree as a starting tree, but introduced random perturbations into it to enable detection of possible convergence problems (using the command "mcmcp nperts = 5 "). A 'corrected' exponential prior on a branch length of $1 / \lambda=0.1 \quad$ ["prset brlenspr $=$ Unconstrained:Exp(100)"] was specified [89]. Convergence of parameter estimates was monitored using Tracer v1.5 [90]. After discarding $25 \%$ of the sampled trees as burnin, posterior probabilities were calculated on the BI stationary sample. Trees and alignments are available at TreeBASE study number 16298.

\section{Divergence time estimation and fossil assignment}

The likelihood ratio test [91] conducted on the BI consensus tree in PAUP* [92] rejected a global molecular clock $(P<0.05)$ for the combined data set. Therefore, divergence times were estimated under a relaxed molecular clock employing the uncorrelated lognormal model [93] in BEAST v1.7 [94]. Eight external time-constraints were imposed for calibration, comprising six fossils [52,95-97] and two secondary calibrations [30] (for details see Additional file 1: Age estimation, calibration). Fossil calibrations were constrained by hard minimum bounds and secondary calibrations by lognormal distributions to incorporate the uncertainty reported in the original study [30]. Two approaches were designed differing only in the assignment of the seed fossil Hypericum antiguum Balueva \& V.P. Nikitin [97]: (i) to the stem node of Hypericum in analysis A, and (ii) to the crown node of Hypericum in analysis B (other calibrations remained unchanged in the two analyses; for a discussion of fossil assignment see Additional file 1: Age estimation, calibration).

A birth and death model of speciation considering incomplete species sampling [98] was set as tree prior. Both divergence time estimations (A and B) were started with two independent Monte Carlo Markov Chain (MCMC) runs, each set to run $10^{8}$ cycles with sampling every $10^{4}$ cycles. The substitution and clock models were not linked between the partitions. The ML tree was used as starting tree. To ensure that the prior branching times of the starting tree fulfilled the constraints imposed by the calibration priors we transformed branch length into absolute time using penalized likelihood [99] with the chronopl command in the $\mathrm{R}$ [100] package ape [101]. Convergence of parameter estimates was monitored using Tracer [90]. The resulting trees were combined in LogCombiner with a burnin of $50 \%$. On the remaining 10,002 trees means and confidence intervals were calculated in TreeAnnotator [94] to obtain the final consensus tree, the ultrametric time calibrated maximum clade credibility (MCC) chronogram that has $95 \%$ of the highest posterior density (HPD). Because missing data can have deleterious effects on analyses that depend on 
branch length [102], we tested the effect on age estimates of missing sequences in our data set. We repeated both analyses (A and B) using a data set that did not contain missing data ('no missing' data) and that had therefore a reduced species sampling containing only 73 accessions (xml input files are available at the Dryad repository [103]).

\section{Ancestral area estimation}

Historical biogeography was analyzed by classifying the species to be distributed within six biogeographic regions, following Brummit et al. [104] for area subdivision. The region were defined to reflect general biogeographic entities, and to be meaningful for the study group: (A) Afrotropical [central Africa, the southern Arabian peninsula, Madagascar, and the West Indian Ocean islands], (WP) western Palearctic, (EP) eastern Palearctic, (IP) Indo-Pacific [SE tropical Asia, Australasia, and the Pacific], (NA) North America [Nearctic], (SA) South America [Neotropic].

We employed a parametric likelihood approach that uses the DEC model [105] implemented in Lagrange [106]. Two models were designed, differing in dispersal probabilities between areas and time to take into account the impact of dispersal/extinction probabilities. The first model (M1) was stratified, i.e. incorporating paleogeographic information on area connectivity, e.g., the existence of land bridges, by varying the dispersal probabilities between areas and over time (Additional file 1: historical biogeography; Additional file 1: Figure S3). The second model (M2) was unconstrained, assuming equal dispersal probabilities between areas over time. Ancestral areas were optimized under both models over 1000 post-burnin posterior trees randomly chosen [107] and generated by divergence time estimation $\mathrm{A}$ and, in a second analysis, by estimation B. Composite Akaike weights [108] were used to summarize the likelihood of range optimizations. Evidence ratios (the ratio of Akaike weights $\left.w_{i} / w_{j}[46]\right)$ were used to evaluate which scenario is the most favored.

\section{Bioclimatic niche analysis}

We used the WorldClim [109] global climate layers considering all 19 Bioclim variables as an approximation of the climatic niche of the species. Collection sites were taken from the voucher specimens, or manually georeferenced (if not documented on the specimen) while comparing voucher information with collection sites per species recorded in the Global Biodiversity Information Facility (GBIF). The bioclimatic variables for each collection locality were extracted using the $\mathrm{R}$ package raster [110]. To identify significant changes in the adaptive landscape (i.e. the climatic niche space) within the study group we employed a reversible-jump Bayesian method of fitting multi-optima Ornstein-Uhlenbeck (OU) models to the bioclim variables [47]. To do so, we first transformed the bioclim variables using a phylogenetic principal components analysis (PCA) [111] in the $\mathrm{R}$ package phytools [112] to obtain principal components (PC) scores per species while correcting for phylogenetic history (i.e. the correlation of independent contrasts [111]). Then, we analyzed the PC1 scores using in the R package bayou [113] with a standard error of 0.5 to estimate the placement and magnitude of shifts in the climatic niche directly from the data [47]. We allowed only one shift per branch and assigned an equal probability of each branch having a shift. We placed a corrected Poisson distribution as prior on adaptive optima and a probability density for a halfCauchy distribution on the number of shifts between adaptive regimes [using make.prior((tree, dists $=$ list (dalpha = "dhalfcauchy", dsig2 = "dhalfcauchy", dsb = "dsb", $\mathrm{dk}=$ "cdpois", $\quad \mathrm{dtheta}=$ "dnorm"), param $=$ list $($ dalpha $=$ list $($ scale $=1), \operatorname{dsig} 2=\operatorname{list}(\mathrm{scale}=1), \mathrm{dk}=\operatorname{list}($ lambda $=15$, $\mathrm{kmax}=200), \mathrm{dsb}=\operatorname{list}(\mathrm{bmax}=1, \operatorname{prob}=1)$, dtheta $=$ list $(-$ mean $=$ mean $($ dat $), \mathrm{sd}=2 * \mathrm{sd}($ dat $))))]$, and run MCMC for $10^{6}$ cycles. To verify that MCMC analyses converged to the same posterior distribution, we applied the Gelman diagnostic [114] in the R package coda [115]. After discarding the first $30 \%$ of samples per run as burnin parameter estimates of the two runs were combined and summarized using the Lposterior command in bayou [113] to obtain a posterior of shift locations and magnitudes, the rate of adaptation $(\alpha)$, and phylogenetic half-life (the amount of time it takes for the expected trait value to get halfway to the phenotypic optimum, defined as $\ln (2) / \alpha$ units of time [56]).

\section{Diversification rate analysis}

We used the Bayesian approach for studying patterns of rate variation through time and among lineages implemented in BAMM (Bayesian analysis of macroevolutionary mixtures) $[116,117]$. The method aims at detecting and quantifying heterogeneity in evolutionary rates by using reversible-jump Markov Chain Monte Carlo to detect subclades that share common parameters of speciation and extinction. BAMM identifies sets of shifts (i.e. configurations) that are sampled together and allows one to compute relative and marginal probability of those configurations (given in the $95 \%$ credible set of distinct shift configurations). We analyzed both the MCC consensus tree produced by divergence time estimation $\mathrm{A}$, and $\mathrm{B}$, respectively (outgroup taxa were removed prior to the analyses to increase statistical power). To do so, we assigned species richness (i.e. sampling fraction) to ten well-supported clades to account for incomplete sampling, and ran MCMC over $10^{8}$ cycles with default settings. Convergence of parameter estimates was evaluated by means of effective samples size (ESS) diagnostics 
using the R package coda [115] after discarding 10\% of samples as burnin. Results were summarized and visualized using the R package BAMMtools [116].

\section{Additional file}

\section{Additional file 1: Phylogenetic inference and topological}

discordance. Figure S1 - Phylogeny of Hypericaceae (detailing species names and node support). Discussion of topological discordance. Age estimation, calibration. Discussion of fossil assignment. Figure S2

MCC chronogram of Hypericaceae (detailing time-constraints). Table S1 Crown group ages of major clades (results of analyses A and B). Historical biogeography. Figure $\mathbf{S 3}$ - Paleogeographical model designed for the stratified ancestral area reconstruction (M1). Table S2 - Summary statistics obtained by optimization of ancestral areas over 1000 trees generated by age estimations $A$ and $B$ detailing results using models $M 1$ and $M 2$. Diversification rate analysis. Figure S4 - Diversification rate shifts obtained by analysis $A$ and $B$, with respective credible sets of distinct shift configurations. Table S3. Results of diversification rate analyses under the different age estimations. Bioclimatic niche analysis. Niche shifts obtained by analysis A and B. Table S3. Results of niche analyses under the different age estimations. Voucher. Species in this study, detailing names, reference, EMBL/Genbank ID, and species distribution (area coding and coordinates). The data sets supporting the results of this article are available in the Dryad repository, http://dx.doi.org/ 10.5061/dryad.4tm8j (BEAST xml input files). Sequence alignments and produced BI/ML trees and are available at the TreeBASE repository http://purl.org/phylo/treebase/phylows/study/TB2:S16298. Original sequence files are stored at the EMBL nucleotide repository, http:// www.ebi.ac.uk/ena/data/view/LK871650-LK871782.

\section{Competing interests}

The authors declare that they have no competing interests.

\section{Authors' contributions}

NMN and FRB designed the study, BG, NMN, and SUC did field work and analyses, NMN wrote the manuscript, and BG, DCT, and FRB contributed to the final version. All authors read and approved the final manuscript.

\section{Acknowledgements}

We thank the herbaria ANDES, B, BM, GH, HEID, K, KYO, PE, TI, Z for allowing us to use their collections. We are grateful to Michael Pirie for discussions on fossil constrains, and Josef Uyeda, Matt Pennell and Luke Harmon for assistance regarding bayou. Tony Verboom and two anonymous reviewers are thanked for valuable comments on the manuscript. This work was supported by the Deutsche Forschungsgemeinschaft (DFG; grant number BL462/8, NU292/1).

\section{Author details \\ ${ }^{1}$ Centre for Organismal Studies Heidelberg, University of Heidelberg, Im Neuenheimer Feld 345, 69120 Heidelberg, Germany. ${ }^{2}$ Department of Biological Sciences, Institute for Bioinformatics \& Evolutionary Studies, University of Idaho, 875 Perimeter MS 3051, Moscow, ID 83844-3051, USA ${ }^{3}$ Institute of Special Botany, Johannes Gutenberg University, Anselm-Franz-von-Bentzelweg 9a, 55099 Mainz, Germany. ${ }^{4}$ Institute of Plant Genetics and Crop Research (IPK), Correnzstrasse 3, 06466 Gatersleben, Germany. ${ }^{5}$ German Centre of Integrative Biodiversity Research (iDiv) Halle-Jena-Leipzig, Deutscher Platz 5e, 04103 Leipzig, Germany.}

Received: 19 November 2014 Accepted: 22 April 2015

Published online: 06 May 2015

\section{References}

1. Darwin C. On the Origin of Species. London: J. Murray; 1859.

2. Harvey PH, Pagel MD. The Comparative Method in Evolutionary Biology. Oxford: Oxford University Press; 1991.

3. Moen D, Morlon H. Why does diversification slow down? Trends Ecol Evol. 2014;29:190-7.
4. Peterson A, Soberón J, Sánchez-Cordero V. Conservatism of ecological niches in evolutionary time. Science. 1999;285:1265-7.

5. Wiens JJ, Graham CH. Niche conservatism: integrating evolution, ecology, and conservation biology. Annu Rev Ecol Evol Syst. 2005;36:519-39.

6. Jablonski D, Roy K, Valentine JW. Out of the tropics: evolutionary dynamics of the latitudinal diversity gradient. Science. 2006;314:102-6.

7. Graham A. A Natural History of the New World. London: The University of Chicago Press; 2011.

8. Donoghue MJ, Bell CD, Li J. Phylogenetic patterns in Northern Hemisphere plant geography. Int J Plant Sci. 2001;162:41-52.

9. Ohlemüller R. Running out of climate space. Science. 2011;334:613-4.

10. Morley RJ. Interplate dispersal paths for megathermal angiosperms. Perspect Plant Ecol Evol Syst. 2003;6:5-20.

11. Zachos J, Dickens G, Zeebe R. An early Cenozoic perspective on greenhouse warming and carbon-cycle dynamics. Nature. 2008;451:279-83.

12. Zachos J, Pagani M, Sloan L, Thomas E, Billups K. Trends, rhythms, and aberrations in global climate 65 Ma to present. Science. 2001;292:686-93.

13. Nauheimer L, Metzler D, Renner SS. Global history of the ancient monocot family Araceae inferred with models accounting for past continental positions and previous ranges based on fossils. New Phytol. 2012;195:938-50

14. Antonelli AA, Sanmartín I. Mass extinction, gradual cooling, or rapid radiation? Reconstructing the spatiotemporal evolution of the ancient angiosperm genus Hedyosmum (Chloranthaceae) using empirical and simulated approaches. Syst Biol. 2011;60:596-615.

15. Manchester SR, Wilde V, Collinson ME. Fossil cashew nuts from the Eocene of Europe: Biogeographic links between Africa and South America. Int J Plant Sci. 2007;168:1199-206.

16. Judd W, Sanders R, Donoghue MJ. Angiosperm family pairs: preliminary phylogenetic analyses. Harvard Pap Bot. 1994:5:1-51.

17. Crisp MD, Arroyo MTK, Cook LG, Gandolfo MA, Jordan GJ, McGlone MS, et al. Phylogenetic biome conservatism on a global scale. Nature. 2009:458:754-6.

18. Ricklefs $\mathrm{R}$, Renner SS. Species richness within families of flowering plants. Evolution. 1994;48:1619-36.

19. Donoghue MJ. A phylogenetic perspective on the distribution of plant diversity. Proc Natl Acad Sci U S A. 2008;105:11549-55.

20. Sakai A, Larcher W. Frost Survival of Plants: Responses and Adaptation to Freezing Stress. Ecological Studies 62. Berlin: Springer Verlag; 1987.

21. Wiens JJ, Donoghue MJ. Historical biogeography, ecology and species richness. Trends Ecol Evol. 2004;19:639-44.

22. Wiens JJ, Kuczynski CA, Townsend T, Reeder TW, Mulcahy DG, Sites JW. Combining phylogenomics and fossils in higher-level Squamate reptile phylogeny: molecular data change the placement of fossil taxa. Syst Biol. 2010;59:674-88

23. Jansson R, Rodriguez-Castaneda G, Harding LE. What can multiple phylogenies say about the latitudinal diversity gradient? A new look at the tropical conservatism, out-of-the-tropics and diversification rate hypotheses. Evolution. 2013;67:1741-55

24. Zanne AE, Tank DC, Cornwell WK, Eastman JM, Smith SA, FitzJohn RG, et al. Three keys to the radiation of angiosperms into freezing environments. Nature. 2014;506:89-92

25. Engler HGA. Versuch einer Entwicklungsgeschichte der extratropischen Florengebiete der nördlichen Hemisphäre. Leipzig: Wilhelm Engelmann; 1879.

26. Baldwin BG, Sanderson MJ. Age and rate of diversification of the Hawaiian silversword alliance (Compositae). Proc Natl Acad Sci U S A. 1998;95:9402-6.

27. Mannion PD, Upchurch P, Benson RBJ, Goswami A. The latitudinal biodiversity gradient through deep time. Trends Ecol Evol. 2013;29:42-50.

28. Escudero M, Hipp AL, Waterway MJ, Valente LM. Diversification rates and chromosome evolution in the most diverse angiosperm genus of the temperate zone (Carex, Cyperaceae). Mol Phylogenet Evol. 2012;63:650-5.

29. Wurdack KJ, Davis CC. Malpighiales phylogenetics: gaining ground on one of the most recalcitrant clades in the angiosperm tree of life. Am J Bot. 2009;96:1551-70

30. Xi Z, Ruhfel BR, Schaefer H, Amorim AM, Sugumaran M, Wurdack KJ, et al. Phylogenomics and a posteriori data partitioning resolve the Cretaceous angiosperm radiation Malpighiales. Proc Natl Acad Sci U S A. 2012;109:17519-24

31. Robson NKB. Studies in the genus Hypericum L. (Guttiferae): 1. Infrageneric classification. Bull Brit Mus (Nat Hist) Bot. 1977;5:291-355. 
32. Robson NKB. Studies in the genus Hypericum L. (Hypericaceae) 9. Addenda, corrigenda, keys, lists and general discussion. Phytotaxa. 2012;72:1-111.

33. Ruhfel B, Bittrich V, Bove C, Gustafsson M, Philbrick C, Rutishauser R, et al Phylogeny of the clusioid clade (Malpighiales): evidence from the plastid and mitochondrial genomes. Am J Bot. 2011;98:306-25.

34. Stevens PF. Hypericaceae. In: Kubitzki K, editor. The Families and Genera of Vascular Plants. Volume XI. Berlin, Heidelberg: Springer Verlag; 2007. p. 194-201.

35. Robson NKB. Hypericum Botany. In: Ernst E, editor. Hypericum - The genus Hypericum. London, New York: Taylor and Francis; 2003. p. 1-22 [Hardman R (Series Editor): Medicinal and Aromatic Plants - Industrial Profiles].

36. Nürk NM, Blattner FR. Cladistic analysis of morphological characters in Hypericum (Hypericaceae). Taxon. 2010;59:1495-507.

37. Nürk NM, Madriñán S, Carine MA, Chase MW, Blattner FR. Molecular phylogenetics and morphological evolution of St. John's wort (Hypericum; Hypericaceae). Mol Phylogenet Evol. 2013;66:1-16.

38. Sanchez Meseguer A, Aldasoro JJ, Sanmartín I. Bayesian inference of phylogeny, morphology and range evolution reveals a complex evolutionary history in St. John's wort (Hypericum). Mol Phylogenet Evol. 2013:67:379-403.

39. Lewis P. A likelihood approach to estimating phylogeny from discrete morphological character data. Syst Biol. 2001;50:913-25.

40. Lemey P, Rambaut A, Drummond AJ, Suchard MA. Bayesian phylogeography finds its roots. PLoS Comput Biol. 2009:5:e1000520.

41. Cohen KM, Finney SC, Gibbard PL, Fan JX. The ICS international chronostratigraphic chart. Episodes. 2013;36:199-204.

42. Robson NKB. Studies in the genus Hypericum L. (Guttiferae): 2. Characters of the genus. Bull Brit Mus (Nat Hist) Bot. 1981;8:55-226.

43. Nürk NM, Scheriau C, Madriñán S. Explosive radiation in high Andean Hypericum - Rates of diversification among New World lineages. Front Genet. 2013:4:1-14.

44. Meseguer AS, Sanmartín I, Marcussen T, Pfeil BE. Utility of low-copy nuclear markers in phylogenetic reconstruction of Hypericum L. (Hypericaceae). Plant Syst Evol. 2014;300:1503-14.

45. Magallón SS, Sanderson MJ. Absolute diversification rates in Angiosperm clades. Evolution. 2001;55:1762-80.

46. Burnham KP, Anderson DR. Model Selection and Multimodel Inference: A Practical Information-Theoretic Approach. 2nd ed. Heidelberg: Springer Verlag; 2002.

47. Uyeda JC, Harmon LJ. A novel Bayesian method for inferring and interpreting the dynamics of adaptive landscapes from phylogenetic comparative data. Syst Biol. 2014;63:902-18.

48. Davis CC, Bell CD, Mathews S, Donoghue MJ. Laurasian migration explains Gondwanan disjunctions: evidence from Malpighiaceae. Proc Natl Acad Sc U S A. 2002;99:6833-7.

49. Tiffney $\mathrm{BH}$. The Eocene North Atlantic land bridge - its importance in Tertiary and modern phytogeography of the Northern Hemisphere. J Arnold Arbor. 1985;66:243-73.

50. Tiffney BH. Phylogeography, fossils, and northern hemisphere biogeography: the role of physiological uniformitarianism 1. Ann Mo Bot Gard. 2008:95:135-43.

51. Denk T, Grímsson F, Zetter R. Episodic migration of oaks to Iceland: evidence for a North Atlantic "land bridge" in the latest Miocene. Am J Bot 2010;97:276-87.

52. Sanchez Meseguer A, Sanmartín I. Paleobiology of the genus Hypericum (Hypericaceae): a survey of the fossil record and its palaeogeographic implications. An Jard Bot Madr. 2012;69:97-106.

53. Tiffney $\mathrm{BH}$, Manchester $\mathrm{S}$. The use of geological and paleontological evidence in evaluating plant phylogeographic hypotheses in the Northern Hemisphere Tertiary. Int J Plant Sci. 2001;162:3-17.

54. Wolfe JA. Some aspects of plant geography of the Northern Hemisphere during the Late Cretaceous and Tertiary. Ann Mo Bot Gard. 1975;62:264-79.

55. Mosbrugger V, Utescher T, Dilcher DL. Cenozoic continental climatic evolution of Central Europe. Proc Natl Acad Sci U S A. 2005;102:14964-9.

56. Hansen TF, Pienaar J, Orzack SH. A comparative method for studying adaptation to a randomly evolving environment. Evolution. 2008;62:1558-5646.

57. Stanley SM. Earth System History. 3rd ed. London: Macmillan Publishers; 2008.

58. Ziman SN, Keener CS. A geographical analysis of the family Ranunculaceae. Ann Mo Bot Gard. 1989:125:1198-205.

59. Kellogg EA. Evolutionary history of the grasses. Plant Physiol. 2001;125:1198-205.

60. Bouchenak-Khelladi Y, Muasya AM, Linder HP. A revised evolutionary history of Poales: origins and diversification. Bot J Linn Soc. 2014;175:4-16.
61. Bouchenak-Khelladi Y, Verboom GA, Savolainen V, Hodkinson TR Biogeography of the grasses (Poaceae): a phylogenetic approach to reveal evolutionary history in geographical space and geological time. Bot J Linn Soc. 2010;162:543-57.

62. Humphreys AM, Linder HP. Evidence for recent evolution of cold tolerance in grasses suggests current distribution is not limited by (low) temperature. New Phytol. 2013;198:1261-73.

63. Sytsma KJ, Walker JB, Schonenberger J, Anderberg AA. Phylogenetics, Biogeography, and Radiation of Ericales. In: Botany 2006: 28 July-02 August 2006; Chico. 2006. p. 435

64. Robson NKB. Studies in the genus Hypericum L. (Guttiferae): 3. Sections 1. Campylosporus to 6a. Umbraculoides. Bull Brit Mus (Nat Hist) Bot. 1985;12:1-325.

65. Robson NKB. Studies in the genus Hypericum L. (Guttiferae): 7. Section 29 Brathys (part 1). Bull Brit Mus (Nat Hist) Bot. 1987;16:1-106.

66. Robson NKB. Studies in the genus Hypericum L. (Guttiferae): 8. Sections 29. Brathys (part 2) and 30. Trigynobrathys. Bull Nat Hist Mus London Bot. 1990;20:1-151.

67. Robson NKB. Studies in the genus Hypericum L. (Guttiferae): 6. Sections 20 Myriandra to 28. Elodes. Bull Nat Hist Mus London Bot. 1996;26:75-217.

68. Robson NKB. Studies in the genus Hypericum L. (Guttiferae) 4(1). Sections 7. Roscyna to 9. Hypericum sensu lato (part 1). Bull Nat Hist Mus London Bot. 2001;31:37-88.

69. Robson NKB. Studies in the genus Hypericum L. (Guttiferae) 4(2). Section 9. Hypericum sensu lato (part 2): subsection 1. Hypericum series 1. Hypericum. Bull Nat Hist Mus London Bot. 2002;32:61-123.

70. Robson NKB. Studies in the genus Hypericum L. (Clusiaceae). Section 9. Hypericum sensu lato (part 3): subsection 1. Hypericum series 2. Senanensia, subsection 2. Erecta and section 9b. Graveolentia. Syst Biodivers. 2006:4:19-98.

71. Robson NKB. Studies in the genus Hypericum L. (Hypericaceae) 5(1). Sections 10. Olympia to 15/16. Crossophyllum. Phytotaxa. 2010;4:5-126.

72. Robson NKB. Studies in the genus Hypericum L (Hypericaceae) 5(2). Sections 17. Hirtella to 19. Coridium. Phytotaxa. 2010;4:127-258.

73. Blattner FR. Direct amplification of the entire ITS region from poorly preserved plant material using recombinant PCR. Biotechniques. 1999;27:1180-6.

74. Löhne C, Borsch T. Molecular evolution and phylogenetic utility of the petD group II intron: a case study in basal angiosperms. Mol Biol Evol. 2005;22:317-32.

75. Taberlet P, Gielly L, Pautou G, Bouvet J. Universal primers for amplification of three non-coding regions of chloroplast DNA. Plant Mol Biol. 1991;17:1105-9.

76. Korotkova N, Schneider J, Quandt D, Worberg A, Zizka G, Borsch T. Phylogeny of the eudicot order Malpighiales: analysis of a recalcitrant clade with sequences of the petD group II intron. Plant Syst Evol. 2009;282:201-28.

77. Drummond AJ, Ashton B, Buxton S, Cheung M, Cooper A, Heled J, et al.: Geneious v5.4 [http://www.geneious.com]. Accessed 17 Nov 2011.

78. Katoh K. MAFFT version 5: improvement in accuracy of multiple sequence alignment. Nucleic Acids Res. 2005:33:511-8.

79. Katoh K, Misawa K, Kuma K-i, Miyata T. MAFFT: a novel method for rapid multiple sequence alignment based on fast Fourier transform. Nucleic Acids Res. 2002;30:3059-66.

80. Castresana J. Selection of conserved blocks from multiple alignments for their use in phylogenetic analysis. Mol Biol Evol. 2000;17:540-52.

81. Felsenstein J. Evolutionary trees from DNA sequences: a maximum likelihood approach. J Mol Evol. 1981;17:368-76.

82. Mau B, Newton MA, Larget B. Bayesian phylogenetic inference via Markov chain Monte Carlo methods. Biometrics. 1999;55:1-12.

83. Stamatakis A. RAxML-VI-HPC: maximum likelihood-based phylogenetic analyses with thousands of taxa and mixed models. Bioinformatics. 2006;22:2688-90.

84. Silvestro D, Michalak I. raxmlGUl: a graphical front-end for RAxML. Org Divers Evol. 2011;12:335-7.

85. Ronquist F, Teslenko M, van der Mark P, Ayres DL, Darling A, Höhna S, et al. MrBayes 3.2: efficient Bayesian phylogenetic inference and model choice across a large model space. Syst Biol. 2012;61:539-42.

86. Stamatakis A, Hoover P, Rougemont J. A rapid bootstrap algorithm for the RAxML web servers. Syst Biol. 2008;57:758-71.

87. Nylander JAA: MrModeltest v2 [https://github.com/nylander/MrModeltest2] Accessed 1 Jan 2013.

88. Posada D, Buckley TR. Model selection and model averaging in phylogenetics: advantages of Akaike information criterion and Bayesian approaches over likelihood ratio tests. Syst Biol. 2004;53:793-808. 
89. Brown JM, Hedtke SM, Lemmon AR, Lemmon EM. When trees grow too long: investigating the causes of highly inaccurate bayesian branch-length estimates. Syst Biol. 2010;59:145-61.

90. Rambaut A, Drummond AJ: Tracer v1.5 [http://beast.bio.ed.ac.uk/Tracer]. Accessed 10 Aug 2009

91. Huelsenbeck JP, Rannala B. Phylogenetic methods come of age: testing hypotheses in an evolutionary context. Science. 1997;276:227-32.

92. Swofford DL: PAUP*. Phylogenetic analyses using parsimony ( ${ }^{*}$ and other methods) v4.0b10. Sinauer Associates; 2002.

93. Drummond AJ, Ho SYW, Phillips MJ, Rambaut A. Relaxed phylogenetics and dating with confidence. PLOS Biol. 2006;4:e88.

94. Drummond AJ, Rambaut A. BEAST: Bayesian evolutionary analysis by sampling trees. BMC Evol Biol. 2007;7:214.

95. Miller NJ, Calkin PE. Paleoecological interpretation and age of an interstadial lake bed in western New York. Quat Res. 1992;37:75-88.

96. Wijninga VM. Neogene ecology of the Salto de Tequendama site (2475 m altitude, Cordillera Oriental, Colombia): the paleobotanical record of montane and lowland forests. Rev Palaeobot Palynol. 1996;92:97-156.

97. Arbuzova O: Hypericum. In Iskopaemye tsvetkovye rastenija Rossii i sopredel'nyh gosudarstv [Fossil flowering plants of Russia and adjacent countries]. Vol IV, Nyctaginaceae-Salicaceae. Edited by Budantsev L. Saint Petersburg; 2005: 48-52

98. Stadler T. On incomplete sampling under birth-death models and connections to the sampling-based coalescent. J Theor Biol. 2009;261:58-66.

99. Sanderson MJ. A nonparametric approach to estimating divergence times in the absence of rate constancy. Mol Biol Evol. 1997;14:1218-31.

100. R Development Core Team: R v3.0.2 [http://www.R-project.org]. Accessed 26 Sep 2013.

101. Paradis E, Claude J, Strimmer K. APE: analyses of phylogenetics and evolution in R language. Bioinformatics. 2004;20:289-90.

102. Lemmon AR, Brown JM, Stanger-Hall K, Moriarty Lemmon E. The effect of ambiguous data on phylogenetic estimates obtained by maximum likelihood and Bayesian inference. Syst Biol. 2009;58:130-45.

103. Nürk NM, Uribe-Convers S, Gehrke B, Tank DC, Blattner FR: Data from: Oligocene niche shift, Miocene diversification - Cold tolerance and accelerated speciation rates in the St. John's Worts (Hypericum, Hypericaceae). Dryad Data Repository; 2015 [http://dx.doi.org/10.5061/dryad.4tm8j]

104. Brummitt RK, Pando F, Hollis S, Brummitt NA. World Geographical Scheme for Recording Plant Distributions. Pittsburgh: Hunt Institute for Botanical Documentation; 2001

105. Ree RH, Moore BR, Webb CO, Donoghue MJ. A likelihood framework for inferring the evolution of geographic range on phylogenetic trees. Evolution. 2005:59:2299-311.

106. Ree RH, Smith SA. Maximum likelihood inference of geographic range evolution by dispersal, local extinction, and cladogenesis. Syst Biol. 2008;57:4-14.

107. Smith SA, Dunn CW. Phyutility: a phyloinformatics tool for trees, alignments and molecular data. Bioinformatics. 2008;24:715-6.

108. Beaulieu JM, Tank DC, Donoghue MJ. A Southern Hemisphere origin for campanulid angiosperms, with traces of the break-up of Gondwana. BMC Evol Biol. 2013;13:80.

109. Hijmans RJ, Cameron SE, Parra $J L$, Jones PG, Jarvis A. Very high resolution interpolated climate surfaces for global land areas. Int J Climatol. 2005;25:1965-78

110. Hijmans RJ: raster: Geographic data analysis and modeling [http://cran. r-project.org/web/packages/raster/index.html]. Accessed 14 Aug 2014.

111. Revell $L$. Size-correction and principal components for interspecific comparative studies. Evolution. 2009:63:3258-68.

112. Revell $L$. phytools: an R package for phylogenetic comparative biology (and other things). Meth Ecol Evol. 2011;3:217-23.

113. Uyeda JC, Eastman J, Harmon L: bayou: Bayesian fitting of Ornstein-Uhlenbeck models to phylogenies [http://CRAN.R-project.org/package=bayou]. Accessed 7 Jul 2014

114. Gelman A, Rubin DB. Inferences from iterative simulation using multiple sequences. Stat Sci. 1992;7:457-511.

115. Plummer M, Best N, Cowles K, Vines K. CODA: convergence diagnosis and output analysis for MCMC. R News. 2006;6:7-11.

116. Rabosky DL. BAMMtools: an R package for the analysis of evolutionary dynamics on phylogenetic trees. J Am Stat Assoc. 2014;90:773-95.

117. Rabosky DL. Automatic detection of key innovations, rate shifts, and diversity-dependence on phylogenetic trees. PLoS One. 2014;9:e89543.

\section{Submit your next manuscript to BioMed Central and take full advantage of:}

- Convenient online submission

- Thorough peer review

- No space constraints or color figure charges

- Immediate publication on acceptance

- Inclusion in PubMed, CAS, Scopus and Google Scholar

- Research which is freely available for redistribution

Submit your manuscript at www.biomedcentral.com/submit 